\title{
Efeito da Hidroterapia na Força Muscular e Capacidade Respiratória em Indivíduos com Síndrome de Down
}

\author{
Janaine Cunha Polese \\ Fisioterapeuta, Mestre em Ciências da Reabilitação (UFMG) e doutoranda em Ciências da Reabilitação (UFMG)/ \\ Health Sciences (University of Sydney), Belo Horizonte-MG, Brasil.
}

Juntamente com o aumento da sobrevida de indivíduos com Síndrome de Down (SD), observa-se o aumento de comorbidades associadas, visto que a história natural da condição de saúde constitui-se pela presença constante dessas ${ }^{1}$. Neste sentido, esforços têm sido realizados na tentativa de promover uma melhor qualidade de vida e maior participação social desta população por meio de estratégias de reabilitação adaptadas e focadas às necessidades específicas de indivíduos com SD. A literatura reporta que a redução da força muscular global é um dos déficits presentes e impactantes em indivíduos com SD, visto que em associação com a hipotonia, a fraqueza é uma das maiores responsáveis pela redução da habilidade de realizar atividades de vida diária²

Além disso, apesar de tradicionalmente os programas de reabilitação reservarem pouca importância ao treinamento da musculatura respiratória, são reportados fraquezas desses músculos em indivíduos com SD quando comparados com indivíduos com mesma idade e sexo ${ }^{3}$. Este é um achado de extrema relevância, uma vez que a fraqueza da musculatura respiratória é associada com a presença de doenças no trato respiratório, que são uma das principais causas de hospitalizaçóes recorrentes nesta população ${ }^{1}$.

O estudo de Castoldi et al. ${ }^{4}$ aborda esse relevante tópico. Os autores avaliaram a força muscular periférica de membros superiores, membros inferiores e forca muscular respiratória de 54 indivíduos com SD antes e após um programa de reabilitação composto por 10 sessóes de hidroterapia, utilizando o método Bad Ragaz. Os autores utilizaram o Teste Muscular Manual para avaliar a força muscular periférica dos membros superiores e inferiores e a Manovacuometria para avaliar indiretamente a força da musculatura respiratória (Pressão Inspiratória Máxima e Pressão Expiratória Máxima). Os autores observaram que o programa resultou em aumento da força de alguns grupos musculares de membros superiores, membros inferiores e um aumento da pressão expiratória máxima, porém não foi capaz de aumentar significativamente a pressão inspiratória máxima. Assim, os autores concluem que a hidroterapia por meio do método Bad Ragaz é um recurso válido no tratamento de indivíduos com SD.

No estudo referido ${ }^{4}$ são apresentados resultados interessantes e que podem ser tomados em parte como base para a prática clínica, uma vez que a hidroterapia pode ser um meio lúdico para tratamento de pacientes com SD, proporcionando resistência devido à turbulência e assim permitindo o fortalecimento muscular. É reportado que a hidroterapia é um método que pode proporcionar tanto melhorias físicas, quanto melhorias psicossociais e mentais para portadores de $\mathrm{SD}^{5}$.

No entanto, deve-se ter cautela na interpretação dos dados do estudo, uma vez que o teste utilizado para avaliação da força muscular não é considerado padrão-ouro para essa mensuração, e assim pode não ter captado diferenças entre as avaliações. Adicionalmente, a manovacuometria é uma medida indireta de forca da musculatura respiratória, o que pode ter influenciado nos resultados. Para comprovação dos efeitos da hidroterapia pelo método de Bad Ragaz na força muscular periférica e forca muscular respiratória de indivíduos com SD, seria extremamente interessante conduzir um estudo com um grupo controle, mensuraçôes mais específicas (como o dinamômetro, por exemplo) e com avaliações cegadas, para assim ser possível utilizar a evidência científica na prática clínica. 


\section{REFERÊNCIAS}

1.Tenenbaum A, Chavkin C, Wexler ID, Korem M, Merrick J. Morbidity and hospitalizations of adults with Down syndrome. Res Devel Disabil 2012;33:435-41.

http://dx.doi.org/10.1016/j.ridd.2011.09.026

2.Gupta S, Rao BK, S DK. Effect of strength and balance training in children with Down's syndrome: a randomized controlled trial. Clin Rehabil 2011;25:425-32.

http://dx.doi.org/10.1177/0269215510382929
3.Silva VZ, França-Barros J, Azevedo M, Godoy JR, Arena R, Cipriano-Jr G. Bone mineral density and respiratory muscle strength in male individuals with mental retardation (with and without Down Syndrome). Res Dev Disabil 2010;31:1585-9.

http://dx.doi.org/10.1016/j.ridd.2010.05.003

4.Castoldi A, Périco E, Grave M. Avaliação da Força Muscular e Capacidade Respiratória em Pacientes com Síndrome de Down Após Bad Ragaz. Rev Neurocienc 2012;20(3):386-91.

5.Campion MR. Hidroterapia: princípios e prática. São Paulo: Ed. Manole, 2000, 334p. 